\title{
SOBOLEV'S THEOREM FOR DOUBLE PHASE FUNCTIONALS
}

\author{
Yoshihiro Mizuta, TAKaO OHno And Tetsu Shimomura
}

Abstract. Our aim in this paper is to establish generalizations of Sobolev's theorem for double phase functionals $\Phi(x, t)=t^{p}+\left\{b(x) t(\log (e+t))^{\tau}\right\}^{q}$, where $1<p \leqslant q<\infty, \tau>0$ and $b$ is a nonnegative bounded function satisfying $|b(x)-b(y)| \leqslant C|x-y|^{\theta}\left(\log \left(e+|x-y|^{-1}\right)\right)^{-\tau}$ for $0 \leqslant \theta<1$.

Mathematics subject classification (2010): 46E30, 42B25, 46E35.

Keywords and phrases: Riesz potentials, fractional maximal functions, maximal functions, Sobolev's theorem, Musielak-Orlicz spaces, double phase functionals, continuity.

\section{REFERENCES}

[1] E. Acerbi And G. Mingione, Regularity results for stationary electro-rheological fluids, Arch. Ration. Mech. Anal. 164 (2002), 213-259.

[2] D. R. Adams And L. I. Hedberg, Function Spaces and Potential Theory, Springer, 1996.

[3] P. Baroni, M. Colombo And G. Mingione, Non-autonomous functionals, borderline cases and relatedfunction classes, St Petersburg Math. J. 27 (2016), 347-379.

[4] P. Baroni, M. Colombo AND G. Mingione, Regularity for general functionals with double phase, Calc. Var. (2018) 57: 62.

[5] B. Bojars Ki AND P. HajŁasz, Pointwise inequalities for Sobolev functions and some applications, Studia Math. 106(1) (1993), 77-92.

[6] C. Capone, D. CruZ-URibe AND A. Fiorenza, The fractional maximal operator and fractional integrals on variable $L^{p}$ spaces, Rev. Mat. Iberoamericana 23 (2007), no.3, 743-770.

[7] Y. CHEN, S. LEVINE AND M. RAO, Variable exponent, linear growth functionals in image restoration, SIAM J. Appl. Math. 66 (2006), no. 4, 1383-1406.

[8] F. Colasuonno AND M. SQuassina, Eigenvalues for double phase variational integrals, Ann. Mat. Pura Appl. (4) 195 (2016), no. 6, 1917-1959.

[9] M. Colombo And G. Mingione, Regularity for double phase variational problems, Arch. Rat. Mech. Anal. 215 (2015), 443-496.

[10] M. Colombo And G. Mingione, Bounded minimizers of double phase variational integrals, Arch. Rat. Mech. Anal. 218 (2015), 219-273.

[11] D. CRUZ-URIBE AND A. FIOREnZA, Variable Lebesgue spaces. Foundations and harmonic analysis. Applied and Numerical Harmonic Analysis. Birkhauser/Springer, Heidelberg, 2013.

[12] L. Diening, Riesz potential and Sobolev embeddings of generalized Lebesgue and Sobolev spaces $L^{p(\cdot)}$ and $W^{k, p(\cdot)}$, Math. Nachr. 263 (2004), no. 1, 31-43.

[13] L. Diening, P. HarJulehto, P. Hëstö And M. R ůžIČKa, Lebesgue and Sobolev spaces with variable exponents, Lecture Notes in Mathematics, 2017, Springer, Heidelberg, 2011.

[14] T. Futamura, Y. Mizuta And T. Shimomura, Sobolev embeddings for variable exponent Riesz potentials on metric spaces, Ann. Acad. Sci. Fenn. Math. 31 (2006), 495-522.

[15] P. Hёsтö, The maximal operator on generalized Orlicz spaces, J. Funct. Anal. 269 (2015), no. 12, 4038-4048; Corrigendum to "The maximal operator on generalized Orlicz spaces", J. Funct. Anal. 271 (2016), no. 1, 240-243.

[16] P. HARJUlehto AND P. HëstÖ, Boundary regularity under generalized growth conditions, Z. Anal. Anwendungen. 38 (2019), no. 1, 73-96.

[17] P. Harjulehto And P. HëstÖ, Orlicz Spaces and Generalized Orlicz Spaces, Lecture Notes in Mathematics, vol. 2236, Springer-Verlag, Berlin, 2019, to appear.

[18] P. HaRjulehto, P. HÄSTÖ AND A. KarpPinen, Local higher integrability of the gradient of a quasiminimizer under generalized Orlicz growth conditions, Nonlinear Anal. 177 (2018), 543-552. 
[19] P. Harjulehto, P. Hästö, V. Latvala and O. Toivanen, Critical variable exponent functionals in image restoration, Appl. Math. Letters 26 (2013), 56-60.

[20] V. KokilashVili AND S. SAmKo, On Sobolev theorem for Riesz, type potentials in the Lebesgue spaces with variable exponent, Z. Anal. Anwendungen 22 (2003), no. 4, 899-910.

[21] J. L. LEWIS, On very weak solutions of certain elliptic systems, Comm. Partial Differential Equations 18(9) (10) (1993), 1515-1537.

[22] F.-Y. Maeda, Y. Mizuta, T. Ohno And T. Shimomura, Boundedness of maximal operators and Sobolev's inequality on Musielak-Orlicz-Morrey spaces, Bull. Sci. math. 137 (2013), 76-96.

[23] F.-Y. Maeda, Y. Mizuta, T. Ohno and T. Shimomura, Sobolev's inequality for double phase functionals with variable exponents, Forum. Math. 31 (2019), no. 2, 517-527.

[24] M. RŮŽIČKA, Electrorheological Fluids: Modeling and Mathematical Theory, Springer-Verlag, Berlin, 2000.

[25] E. M. STEIN, Singular integrals and differentiability properties of functions, Princeton Univ. Press, Princeton, 1970. 